\title{
Diurnal phase of late-night against late-afternoon of stratiform and convective precipitation in summer southern contiguous China
}

\author{
Rucong Yu • Weihua Yuan · Jian Li • \\ Yunfei Fu
}

Received: 27 December 2008/Accepted: 25 March 2009/Published online: 21 April 2009

(C) The Author(s) 2009. This article is published with open access at Springerlink.com

\begin{abstract}
Using the tropical rainfall measuring mission (TRMM) Precipitation Radar (PR) observations combined with the surface rain gauge data during 1998-2006, the robust diurnal features of summer stratiform and convective precipitation over the southern contiguous China are revealed by exploring the diurnal variations of rain rate and precipitation profile. The precipitation over the southern contiguous China exhibits two distinguishing diurnal phases: late-night (2200-0600 LST) and late-afternoon (14002200 LST), dependent on the location, precipitation type and duration time. Generally, the maximum rain rate and the highest profile of stratiform precipitation occur in the late-afternoon (late-night) over the southeastern (southwestern) China, while most of the stratiform short-duration rain rate tends to present late-afternoon peaks over the southern China. For convective precipitation, the maximum rain rate and the highest profile occur in the lateafternoon over most of the southern contiguous China, while the convective long-duration rain rate exhibits late-
\end{abstract}

R. Yu $\cdot$ W. Yuan $\cdot$ Y. Fu

LASG, Institute of Atmospheric Physics,

Chinese Academy of Sciences, Beijing, China

R. Yu $(\bowtie) \cdot$ J. Li

LaSW, Chinese Academy of Meteorological Sciences,

China Meteorological Administration, Beijing, China

e-mail: yrc@cma.gov.cn; yrc@lasg.iap.ac.cn

W. Yuan

Graduate School of the Chinese Academy of Sciences,

Beijing, China

Y. Fu

Laboratory of Satellite Remote Sensing and Climate

Environment, University of Science and Technology of China,

Hefei, Anhui, China night peaks over the southwestern China. Without regional dependence, the convective precipitation exhibits much larger amplitude of diurnal variations in both near surface rain rate and vertical extension compared with stratiform precipitation and the convective rain top rises most rapidly between noon and afternoon. However, there are two distinctive sub-regions. The diurnal phases of precipitation there are very weakly dependent on precipitation type and duration time. Over the eastern periphery of the Tibetan Plateau, the maximum rain rate and the highest profile of either convective or stratiform precipitation occur in the late-night. Over the southeastern coastal regions, both the near surface rain rate and rain top of convective and stratiform precipitation peak in the late-afternoon.

Keywords Diurnal cycle $\cdot$ Stratiform precipitation . Convective precipitation $\cdot$ Rainfall duration

\section{Introduction}

Due to its significant influences on Earth's weather and climate, the diurnal cycle of precipitation has been widely studied using both ground based rain gauge records and satellite observations (Wallace 1975; Dai et al. 1999; Dai 2001; Yang and Slingo 2001; Sorooshian et al. 2002; Nesbitt and Zipser 2003). Large differences exist in the diurnal variations between the open oceans and the continents. The diurnal amplitude is usually larger over the continents than open oceans. Oceanic deep convection tends to reach its maximum in the early morning and continental convection generally peaks in the late afternoon. Moreover, affected by the complex land-sea and mountain-valley breezes, there are interesting regional variations over the continents (Yang and Slingo 2001). The 
mainland of China not only occupies the largest continental area over East Asia Monsoon region, but also is characterized by complex land-sea contrast and irregular mountain-valley distributions. Therefore, the contiguous China exhibits unique climatic characteristics. Using rain gauge records, Yu et al. (2007a) pointed out that summer precipitation over the contiguous China has distinct diurnal variations with considerable regional features. Over the southern inland China and northeastern China, summer precipitation peaks in the late afternoon, while over the eastern periphery of the Tibetan Plateau it peaks around midnight. To further understand the diurnal variation of rainfall over the central eastern China, Yu et al. (2007b) classified the precipitation into different categories based on the duration time. The results suggest that the duration of a rainfall event is a critical factor to determine the diurnal phase. Their results show that long-duration rainfall events tend to have their maximum hourly rainfall around the early morning, while short-duration rainfall events tend to peak around the late afternoon. The seasonal variation of rainfall diurnal cycle in the southern contiguous China was also examined by Li et al. (2008) and it is both regional and durational dependent.

Based on rain gauge data, analyses of diurnal cycle are mainly focused on the rainfall amount and frequency of all kinds of precipitation. Nevertheless, the total rainfall is constituted of the stratiform precipitation associated with relative stable stratification and convective precipitation related to vigorous overturning. Analysis of the components modulated by different mechanisms would be helpful to understand the characteristics of total rainfalls. Meanwhile, differences exist in the vertical distributions of latent heating and horizontal mass divergence between stratiform and convective precipitation regions. Investigating them separately would be useful to better measure the feedback of total rainfalls to the atmosphere (Houze 1997). Previous researches have been mostly focused on the diurnal phase and amplitude of precipitation amount, frequency, intensity and the like, but the diurnal variation of the precipitation vertical structure is rarely revealed. Tao et al. (1993) pointed out that the precipitation profile reflects both microphysical and thermal-dynamical processes associated with precipitation formation. For example, the mean profile patterns of convective and stratiform precipitation are different. The former usually has three (or four) layers from rain top to near surface: crystal, mixed ice and water, and droplet collision (evaporation) layer. In contrast, the latter commonly has three layers: crystal, mixed ice and water, and water layer (Liu and Fu 2001; Fu et al. 2003, 2006).

TRMM 2A25 products can offer both the precipitation types and three dimensional rainfall structures (Iguchi et al. 2000). Moreover, as a non-sun-synchronous satellite, during its precession period it samples rainfall at different times throughout the diurnal cycle. To be noted, the reflectivity-rain-rate algorithm used to produce the TRMM $2 \mathrm{~A} 25$ products can provide a more physically direct measurement of near surface rainfall than other remote sensing proxies like IR cloud-top temperatures and low-frequency microwave brightness temperatures (Nesbitt and Zipser 2003). In this paper, $2 \mathrm{~A} 25$ products derived from the TRMM PR measurements are used to explore the fundamental diurnal property of two kinds of rainfall events in the southern contiguous China, and the data sets are compared with hourly rain gauge records to investigate the diurnal variations of rainfall events with different duration. It will reinforce the knowledge about regional features of diurnal variations and the corresponding mechanisms.

The rest of this paper is organized as follows: Section 2 describes the datasets and analysis method; the diurnal features of stratiform and convective precipitation are presented in Sect. 3; the diurnal features of stratiform and convective precipitation with long and short duration are discussed in Sect. 4. Section 5 describes the rainfall diurnal variations of two distinctive sub-regions. A summary and discussion are given in Sect. 6.

\section{Data and methodology}

The data used in this study is the TRMM standard 2A25 products measured by TRMM PR in summer (June, July and August) from 1998 to 2006. TRMM PR is an electric scanning radar operating at $13.8 \mathrm{GHz}$. It scans $\pm 17^{\circ}$ from nadir with 49 positions, resulting in a $215 \mathrm{~km}$ swath width and a horizontal resolution of $4.3 \mathrm{~km}$ at nadir. The resolution along the radar beam is $250 \mathrm{~m}$. The $2 \mathrm{~A} 25$ products contains rain rate profiles $(\mathrm{R})$, which are calculated from the radar reflectivity $(\mathrm{Z})$ profiles using a Z-R relation based on a hybrid of the Hitschfeld-Bordan method and the surface reference method (Iguchi et al. 2000). Errors in a given PR 2A25 near surface rainfall estimate may be introduced due to uncertainties in the attenuation correction, drop size distribution, and nonuniform beamfilling assumptions. However, it is unlikely that these errors are large, or would significantly affect the results portraying the phase and amplitude of the diurnal cycle (Nesbitt and Zipser 2003). Furthermore, PR pixels are classified into three types: convective, stratiform, and "other", according to the vertical pattern of the profile (i.e. V-method) and the horizontal variability of the echo (i.e. H-method (Steiner et al. 1995)). Simply, a stratiform profile is classified if PR detects a brightband near the freezing level in the profile. If no brightband exists and any value of radar reflectivity in the beam exceeds a predetermined value of $39 \mathrm{dBZ}$, the profile is named as convective. Exception for both convective and stratiform, profile is labeled as "other". 
Stratiform and convective precipitation will be the focus in this article. When total precipitation is referred, it concludes all three kinds of precipitation: stratiform, convective, and "other".

The TRMM satellite with an orbit inclination of roughly $35^{\circ}$ provides data between approximately $\pm 36^{\circ}$ latitude. However, the narrow swath of the PR data $(215 \mathrm{~km})$ leads to geographic undersampling on a daily basis. The orbital pattern of the satellite allows sampling between 0.5 times per day at the equator and nearly 2 times per day at $35^{\circ}$ latitude (Nesbitt and Zipser 2003). Therefore, the swath data is inhomogeneous both spatially and temporally. As analyses were applied in $0.5^{\circ} \times 0.5^{\circ}$ grid cells, correction is applied to the samples, according to the weights between the observation number of the whole region $\left(22-32^{\circ} \mathrm{N}\right.$, $\left.100-122^{\circ} \mathrm{E}\right)$ and that of each grid cell, as well as the weights between the observation number of each hour and the total number in the same grid cell. Because the sensitivity of PR is about $17 \mathrm{dBZ}$, which corresponds to about $0.7 \mathrm{~mm} / \mathrm{h}$ in rain rate, only records with near surface rain rate no less than $1 \mathrm{~mm} / \mathrm{h}$ are kept in this study.

As its non-geosynchronous orbit, TRMM can not describe the persistence of a rainfall event individually, thus some comparison is made between the ground based rain gauge data and TRMM $2 \mathrm{~A} 25$ products to investigate different duration rainfall events detected by the satellite. The surface precipitation data used in this study are collected and compiled by the National Meteorological Information Centre of China Meteorological Administration (Yu et al. 2007a). It consists of quality-controlled hourly rain gauge records from 1998 to 2006 at 156 stations located in the southern China (shown in Fig. 2a). The summer rainfalls are classified according to their duration without any intermittence or at most one-hour intermittence during a single rainfall event. The rainfall events lasting more than $6 \mathrm{~h}$ (last less than $3 \mathrm{~h}$ ) are defined long(short-) duration rainfall events (Yu et al. 2007b). Two cases are shown in Fig. 1 to give a vivid image to the comparison between the station hourly rainfall data and the satellite records. The two rainfall cases occurred on August 13th 2000 ( $a$ and b) and August 22nd 2000 (c and d). Figure 1a, c exhibit the distributions of the precipitation pixels detected by the PR. Figure $1 b$, d present the hourly rainfall amount of the whole rainfall process observed by the station rain gauge. The arrows point out the time of the satellite observations. As Fig. 1 shows if a rainfall event is measured by a rain gauge and TRMM's orbit covers this region during the raining period, the duration of precipitation detected by TRMM follows the rain gauge data. When two or more surface rain gauges are within one TRMM snapshot scan, the precipitation detected by TRMM is defined long-duration precipitation, as long as a long-duration rainfall is observed by any rain gauge.
To effectively describe the diurnal cycle, statistics on precipitation peaks and profiles are made in 6 local solar time (LST) periods defined as the midnight (from 2200 LST to 0200 LST), early morning (from 0200 LST to 0600 LST), morning (from 0600 LST to 1000 LST), noon (from 1000 LST to 1400 LST), afternoon (from 1400 LST to 1800 LST), and evening (from 1800 LST to 2200 LST).

\section{Precipitation type dependent diurnal features}

The spatial distributions of diurnal phases of total, stratiform, and convective precipitation are shown in Fig. 2. The diurnal peak of the total rain rate (Fig. 2a) occurs in the afternoon and evening over most of the eastern part of the southern contiguous China. By contrast, rain rate over a large portion of the western part of the southern contiguous China shows nocturnal (2200-0600 LST) peaks. In terms of the peak time, the southern contiguous China is divided into two parts: Region A and Region B (as marked in Fig. 2). The difference between the two adjacent regions is consistent with the conclusions of previous studies deduced from the hourly station rain-gauge data (Yu et al. 2007a; Li et al. 2008). Figure $2 b$ and $c$ show the diurnal peak of stratiform and convective rain rate, respectively. The diurnal peak of the stratiform rain rate presents a sharp contrast between the two regions. The stratiform rainfall peak occurs during the late-night (2200-0600 LST) over $52.5 \%$ of Region A, while the stratiform precipitation peaks in the late-afternoon (1400-2200 LST) over 63.8\% of Region B. However, the phase contrast between the southwestern and southeastern China disappears in convective rainfall (Fig. 2c). Over $76.2 \%$ of the southern contiguous China, convective rainfall shows a late-afternoon peak. Nevertheless, over the eastern edge of the Tibetan Plateau, the convective rain rate peaks around the late-night. Although this late-night precipitation occurs only over a small portion (15.03\%) of the southern China, it reflects the great influence of the Tibetan Plateau to regional climate. Analysis also shows that the peak time of precipitation frequency is quite similar with that of the rain rate.

Diurnal features of the regional averaged stratiform and convective rain rate are investigated respectively (figure not shown). For stratiform precipitation, the averaged maximum rain rate occurs in the late-night (0400 LST) in Region A and late-afternoon (1500 LST) in Region B. The averaged maximum convective precipitation appears in the late-afternoon (1500 LST) over the two regions and a secondary late-night peak at 0000 LST exists in Region A. In addition to the rain rate, diurnal features of regional averaged rainfall profile are also assessed (Fig. 3). Both the rain top and near surface rain rate of stratiform 
Fig. 1 The distributions of precipitation pixels of two rainfall processes observed by TRMM PR. The black dots represent the position of the station rain gauge and red (green) dots denote the convective (stratiform) precipitation pixels. $\mathbf{b}(\mathbf{d})$ for the hourly rainfall amount of the whole rainfall process observed by the station rain gauge corresponding to the satellite observation shown in a (c). The arrows point out the time of the satellite observations
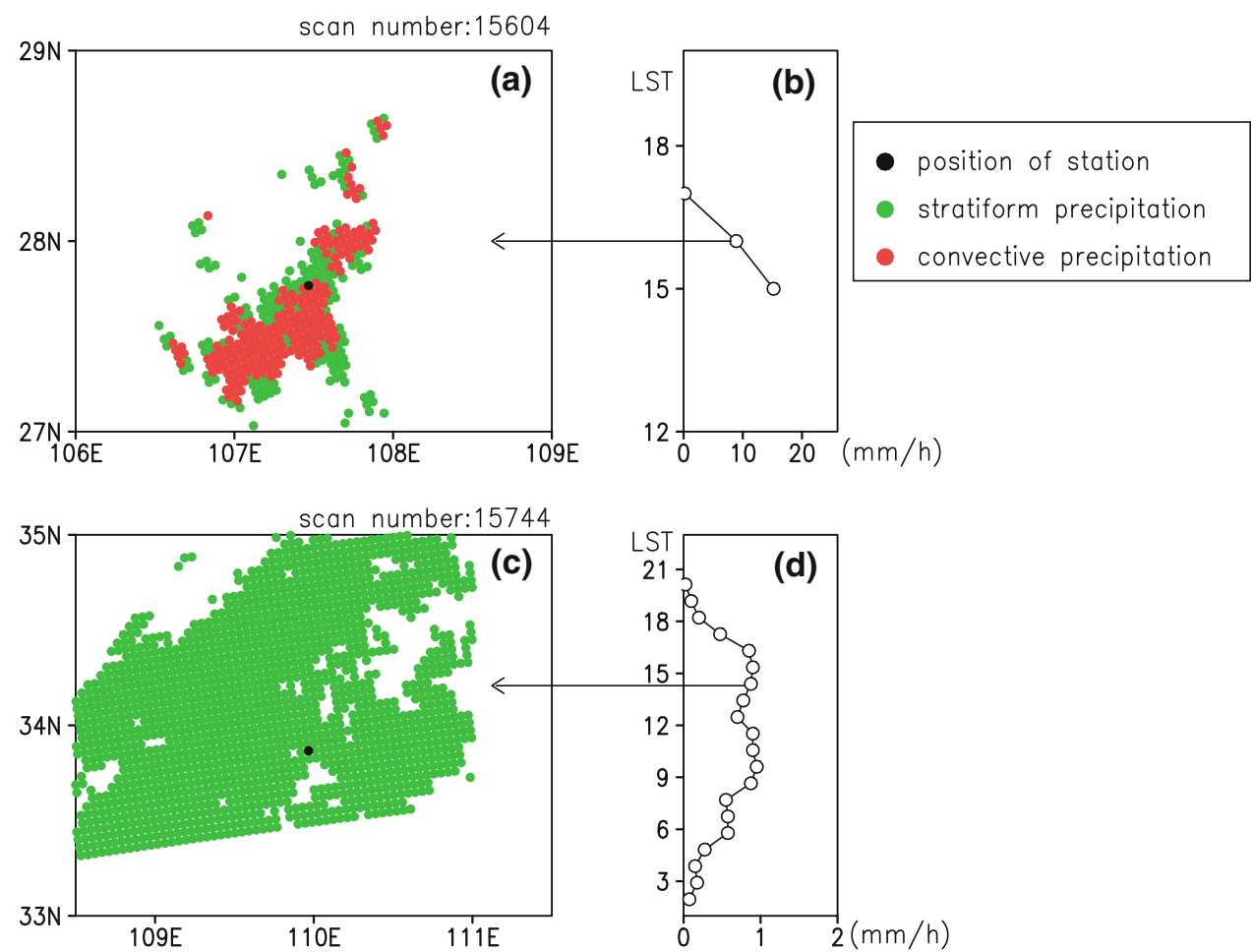

precipitation peak at midnight in Region A (Fig. 3a). In Region B (Fig. 3b), the rain top of stratiform precipitation peak in the evening, but the near surface rain rate gets to the maximum in the afternoon. Compared with the stratiform rain rate profile, the convective precipitation profile shows much stronger diurnal variations (Fig. 3c, d). The convective rain top and near surface rain rate in both Region A and Region B peak in the afternoon. During the $4 \mathrm{~h}$ between noon and afternoon, the rain top shows the maximum rise in both Region $\mathrm{A}$ and Region $\mathrm{B}$. This uniform quick strengthening of convection might be caused by the favorable thermal condition in the afternoon. Over the southern contiguous China, the minimum stratiform precipitation occurs in the noon, and the convective precipitation reaches the lowest level in the morning.

The diurnal phase of total precipitation is more similar to that of stratiform (convective) precipitation in Region A (B). For precipitation in Region A, the percentage contribution of stratiform precipitation is about $52.8 \%$ and convective precipitation of $46.5 \%$. For precipitation in Region $\mathrm{B}$, the proportion of stratiform precipitation is $44.1 \%$, contrast to the convective composition of $54.5 \%$. The stratiform (convective) precipitation occupies a large part of the total precipitation in Region A (B). While over the southern contiguous China, both the stratiform and convective precipitation have almost equally contribution to total precipitation. The convective precipitation occupies about $47.3 \%$ of total precipitation, compared to stratiform precipitation of 51.0\%. Previous studies (Yu et al. 2004; Li et al. 2008) mentioned that large cloud and cloud thickness are found in the southwestern China, producing extremely strong negative short wave cloud radiative forcing. As a result, the surface air temperature is relatively low in the afternoon over the southwestern China. Therefore it is unfavorable for the occurrence of the afternoon convection. This might be a reason why the composition of convective precipitation is relatively lower in the southwestern China.

\section{Duration related diurnal features}

The peak time of both the rain rate and precipitation profiles are closely related to the precipitation type. The time when the maximum hourly rainfall occurs also depends on the rainfall duration ( $\mathrm{Yu}$ et al. 2007b; Li et al. 2008). Averaged over the southern China (Fig. 4a), both the stratiform and convective long-duration rainfalls peak in the early-morning (0400 LST) and the two types of shortduration rainfalls tend to present late-afternoon peaks (1500 LST). Using the rain gauge data, Li et al. (2008) investigated the different diurnal features of the long- and short-duration rainfall events between the southeastern and the southwestern China. They concluded that the longduration rainfall events over the southwestern China show dominant late-night peaks and usually have a late-afternoon maximum over the southeastern China. By contrast, short-duration precipitation over most of the southern China reaches the maximum in the late-afternoon. The 

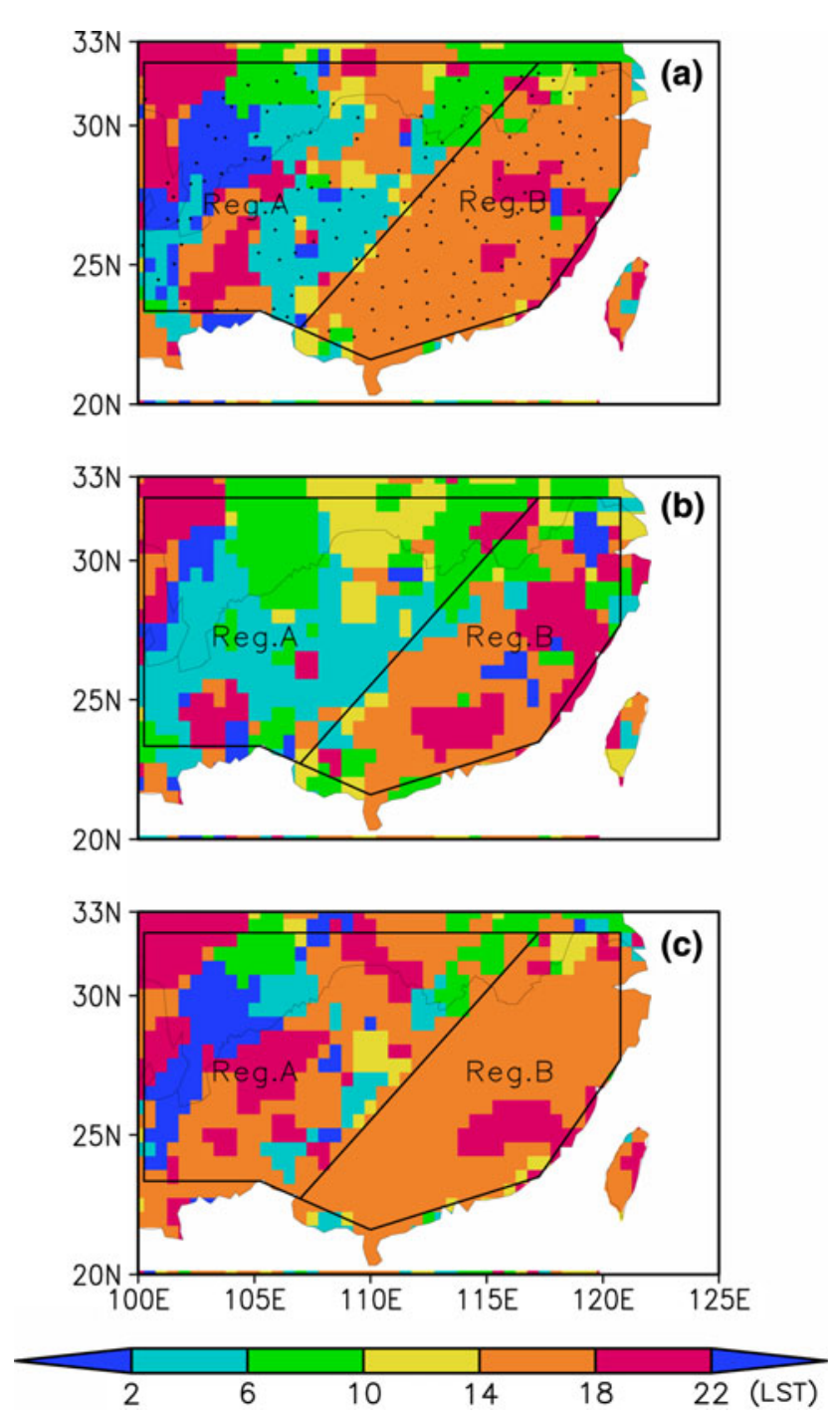

Fig. 2 Spatial distributions of the diurnal phase of summertime mean (a) total (b) stratiform and (c) convective rain rate detected by TRMM PR during 1998-2006. The location of the Yangtze River is drawn as a black line. Two distinct regions are labeled. The locations of 156 rain gauge stations used in this study are marked in (a)

diurnal phases of stratiform and convective precipitation with different duration over the southeastern and southwestern China are analyzed below.

Diurnal cycle of regional averaged stratiform and convective precipitation with different duration is shown in Fig. 4b, c. As shown in Fig. 4b, both the long- and shortduration stratiform rainfalls show a late-night (0400 LST) peak over Region A and tend to peak in the late-afternoon (1600 LST) over Region B. To be noted, the diurnal amplitude of long-duration rainfall is larger than that of short-duration precipitation over Region A and a secondary peak at 0500 LST exits in rainfalls over Region B. For convective precipitation (Fig. 4c), the long-duration rainfalls peak at 0300 LST and short duration rainfall has the maximum hourly rainfall at 1500 LST over Region A. Over the southeastern China, both the long- and short-duration rainfalls peak in the late-afternoon. Similar to the stratiform long-duration precipitation, the convective long-duration precipitation also has a secondary peak in the late-night over Region B.

The spatial distributions of diurnal phase of the long (short)-duration rainfalls are shown in (Figs. 5 and 6). For long-duration rainfall events, the diurnal peak of stratiform precipitation occurs in the late-night over $62.3 \%$ of Region A (Fig. 5a). Different from Fig. 2c, the convective longduration precipitation (Fig. 5b) exhibits a maximum hourly rainfall in the late-night over $54.9 \%$ of Region A. Over the southeastern coastal area, the late-afternoon peak is predominant for either stratiform or convective long-duration precipitation. For short-duration rainfall events, stratiform precipitation over $55.1 \%$ of the southern China peaks in the late-afternoon (Fig. 6a), which is quite different from Fig. 2b. The late-afternoon peak of convective precipitation controls $75.7 \%$ of the southern China (Fig. 6b). Over the eastern periphery of Tibetan Plateau, both convective and stratiform precipitation peak in the late-night.

\section{Diurnal features of two sub-regions}

Synthesis of analyses presented above suggests that the diurnal phase of precipitation over most areas of the southern contiguous China is dependent on both precipitation type and duration time. However, over Region A (Region B) there is a unique sub-region, where convective and stratiform precipitation as well as long-duration and short-duration precipitation all peak in the late-night (lateafternoon), and it is named as sub-Region A (sub-Region B). As shown in Fig. 7, rainfall in the eastern periphery of Tibetan Plateau has a solid late-night peak and precipitation has a consistent late-afternoon maximum over some southeastern coastal and inland mountain regions.

The diurnal cycle of stratiform and convective precipitation averaged over the two sub-regions is shown in Fig. 8. Stratiform precipitation over sub-Region A peaks in the late-night (0400 LST) and the rain rate reaches the minimum at noon and then increases in the evening (Fig. 8a). The convective rain rate over sub-Region A also reaches the maximum in the late-night (0000LST). Notably, there is a significant lag between the diurnal phase of convective and stratiform precipitation over sub-Region A in the late-night. The peak time of convective rain rate leads that of stratiform rain rate by about $4 \mathrm{~h}$. As shown in Fig. 8b, both the stratiform and convective rainfalls over sub-Region B present a strong peak at 1500 LST. A secondary peak of stratiform precipitation can be found at 
Fig. 3 Diurnal variation of the precipitation profiles averaged over Region A and Region B. a (b) for the mean stratiform rain rate profile over Region $A$ (Region B); c (d) same as a (b), but for convective rain rate
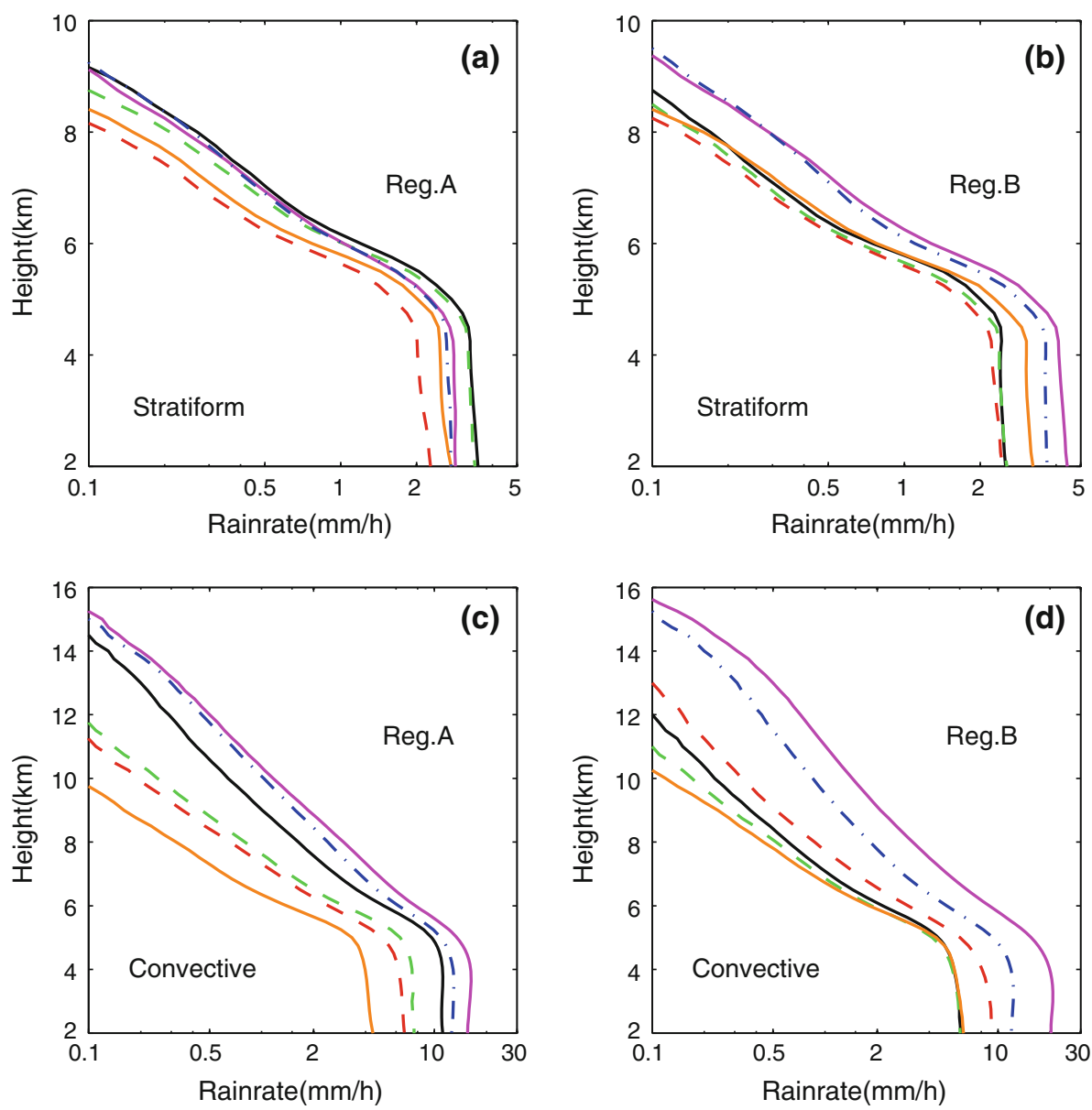

2100 LST. From midnight to noon, the rain rate keeps to be low.

Figure 9 shows the profiles of convective and stratiform rain rate averaged in 4-h period. The area selected in Fig. 9 is the same as in Fig. 8. Figure 9a and b show the profiles of stratiform rain rate. Different from Fig. $3 \mathrm{a}$, the mean profile of stratiform precipitation over sub-Region A rises most rapidly between the evening and midnight (Fig. 9a). The near surface rain rate and rain top peak in the early morning. Then the height of the profile is significantly reduced and reaches the lowest at noon. The profile of stratiform rain rate over sub-Region $B$ reaches the lowest level in the early morning (Fig. 9b). In the following several hours it develops and the maximum near surface rain rate appears in the afternoon, but the rain top rises to the highest in the evening. After the evening, the height of the profile decreases rapidly and is kept at a low level from midnight to noon. Figure 9c shows the mean profile of convective rain rate averaged over sub-Region A. Different from Fig. 3c, the mean top of the convective precipitation increases from the lowest at noon to the highest at midnight. The rain top has a comparable rise (about $2 \mathrm{~km}$ ) between evening and midnight with that (about $2.5 \mathrm{~km}$ ) between the noon and afternoon. Consistent with rain rate, the peak time of the convective precipitation profile leads that of stratiform profile by about $4 \mathrm{~h}$. Figure $9 \mathrm{~d}$ shows the profile of convective rain rate over sub-Region $\mathrm{B}$. The lowest height of the convective precipitation appears in the early morning. The convection becomes stronger at noon and reaches the highest in the afternoon when the near surface rain rate also peaks. After evening, the top decreases quickly to the lowest in the early morning. 

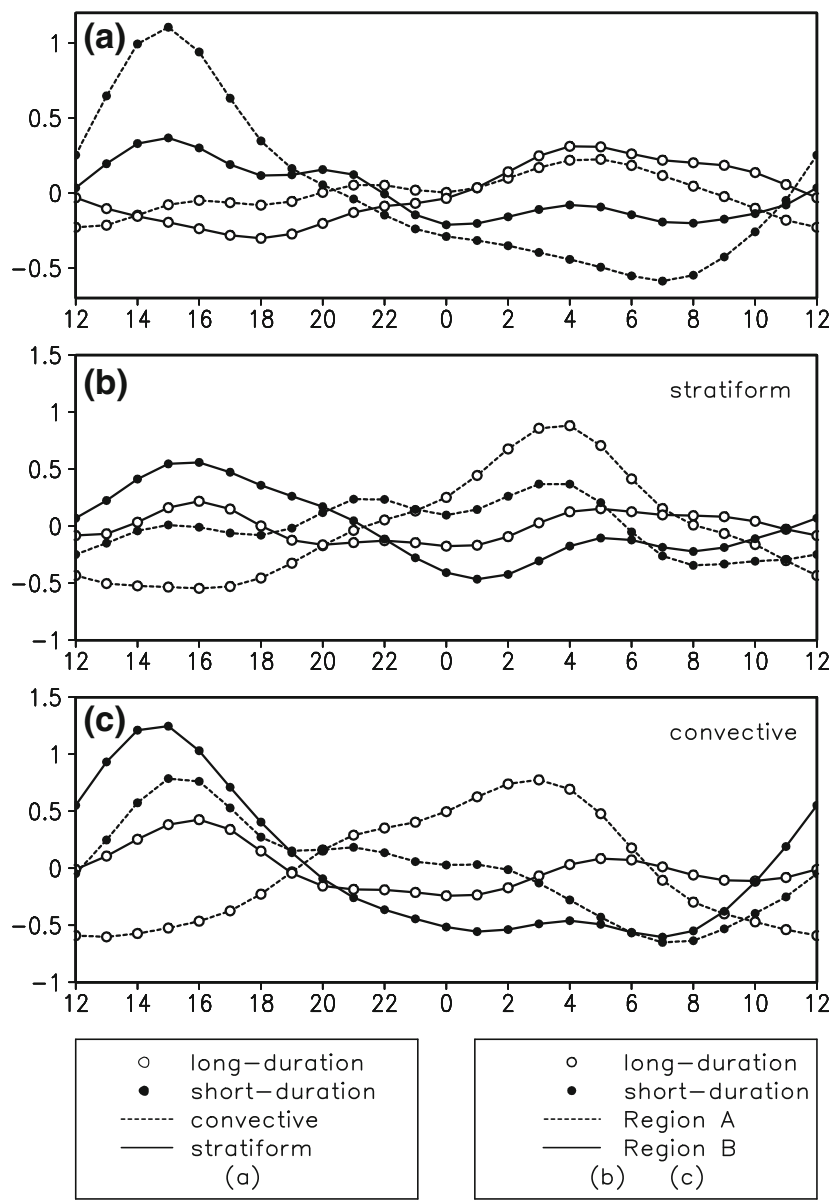

Fig. 4 a The diurnal variation of the stratiform long-duration (solid line with open circle) and short-duration (dot-solid line) rain rate, as well as convective long-duration (dash line with open circle) and short-duration (dot-dash line) rain rate averaged over the southern China. b The diurnal variation of the regional averaged stratiform long-duration rain rate over Region A (dash line with open circle) and Region B (solid line with open circle), as well as stratiform shortduration rain rate over Region A (dot-dash line) and Region B (dotsolid line). c Same as (b), but for convective rain rate

\section{Summary and discussion}

The diurnal characteristics of summer rain rate and profiles with different types and duration over the southern contiguous China are examined by the TRMM 2A25 products during 1998-2006. The major conclusions are summarized below.

1. The maximum rain rate and the highest profile of stratiform precipitation occur in the late-afternoon (late-night) over the southeastern (southwestern) China. For convective precipitation, the maximum rain rate and the highest profile occur in the lateafternoon over most of the southern contiguous China.

2. The diurnal phase of stratiform and convective precipitation also relates to the rainfall duration. For
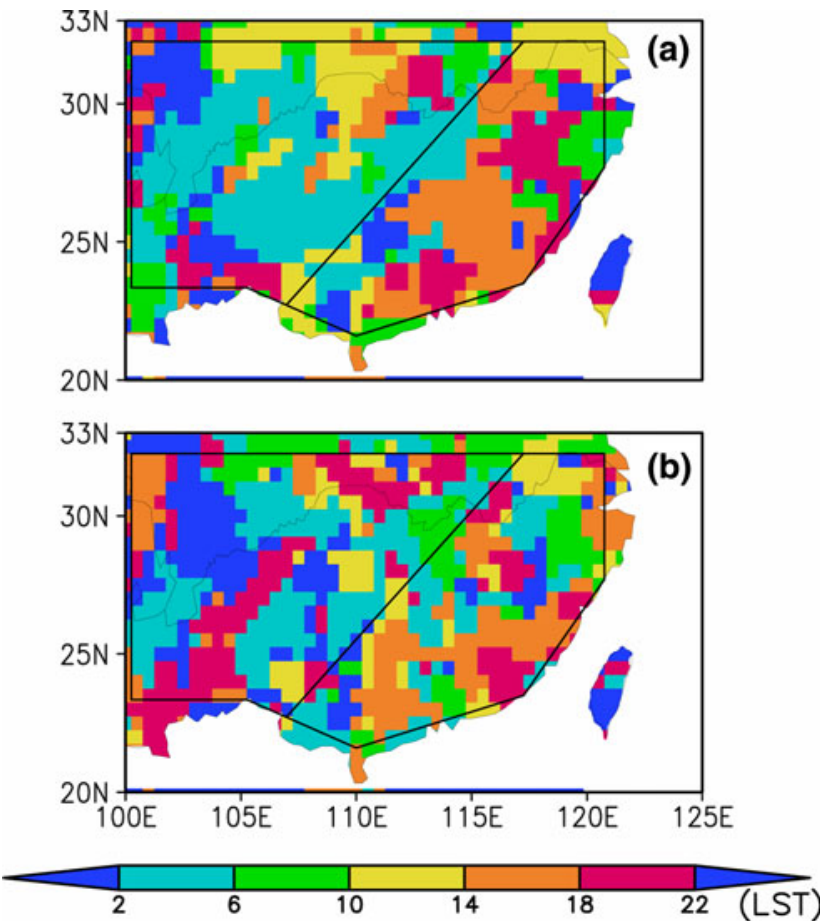

Fig. 5 Same as Fig. 2, but (a) for stratiform long-duration rainfall events and (b) for convective long-duration rainfall events
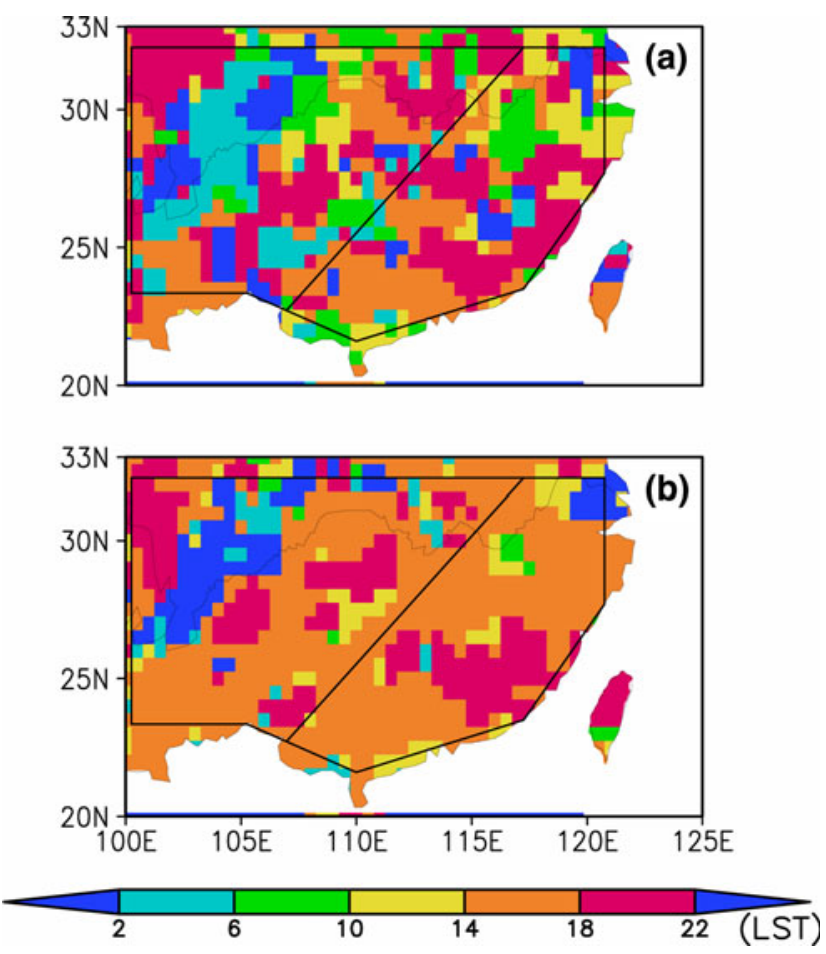

Fig. 6 Same as Fig. 2, but (a) for stratiform short-duration rainfall events and (b) for convective short-duration rainfall events

long-duration rainfall events, most of the stratiform and convective precipitation exhibit late-night peaks except for the rainfall in the southeastern coastal 
Fig. 7 The black boxes present the areas in which the stratiform and convective, as well as the long-duration and short-duration rainfalls all peak in the latenight (late-afternoon) over Region A (Region B). The shading denotes terrain heights (in $\mathrm{m}$ )

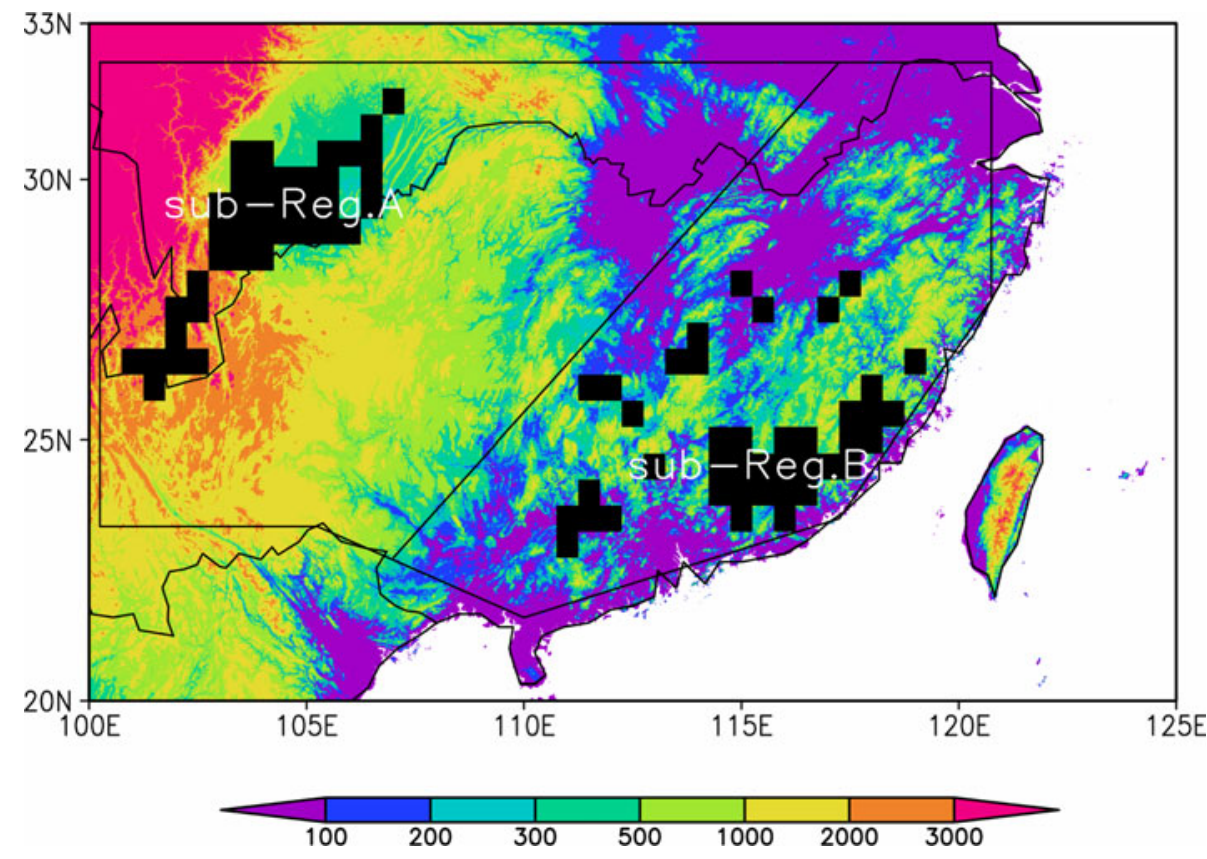

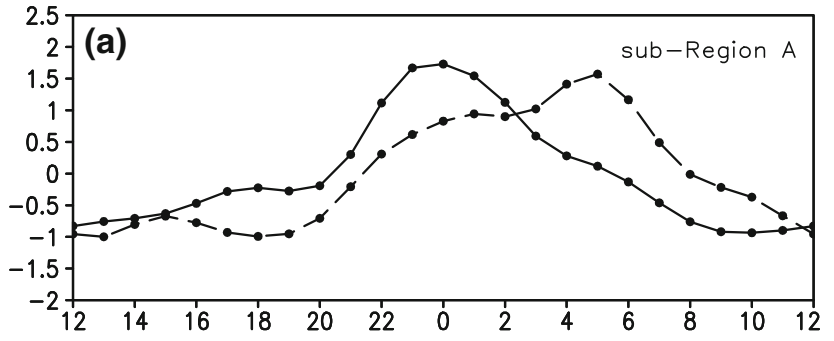

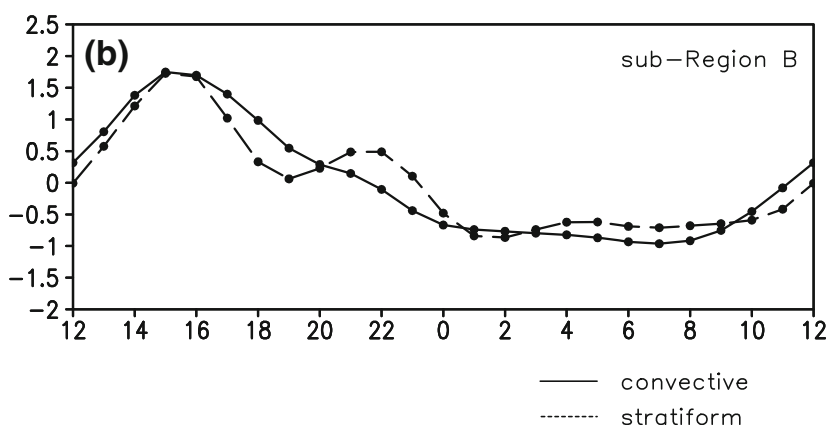

Fig. 8 Diurnal variation of the normalized stratiform and convective rain rate averaged in (a) sub-Region A and (b) sub-Region B. The dashed (solid) line represents the stratiform (convective) rain rate. The horizontal axis corresponds to the local solar time

regions. For short-duration rainfall events, most of two types of precipitation tend to present late-afternoon peaks, apart from the rainfall over the eastern periphery of the Tibetan Plateau.

3. There are two distinct sub-regions where the diurnal phases are very weakly dependent on precipitation type and duration time. Over the eastern periphery of the Tibetan Plateau, the maximum rain rate and the highest profile of either convective or stratiform precipitation occur in the late-night and the peak time of convective rain rate leads that of the stratiform rain rate by about $4 \mathrm{~h}$. Over some southeastern coastal and inland mountain regions, the near surface rain rate and rain top of both convective and stratiform precipitation peak in the late-afternoon.

4. Without regional dependence, the convective precipitation exhibits much larger diurnal amplitude in both near surface rain rate and vertical extension compared with stratiform precipitation. The convective rain top rises most rapidly between noon and afternoon.

Using station rain gauge data, Li et al. (2008) has discussed the differences in rainfall diurnal cycle between the southwestern and southeastern China. In this study, the diurnal phase of stratiform rain rate derived from TRMM PR measurements shows similar pattern with that of the total rainfall derived from the rain gauge data over the southwestern China. This similarity indicates that the stratiform precipitation plays an important role in modulating the late-night peak in the southwestern China.

The late-afternoon peaks of the stratiform and convective short-duration rainfalls occupy a large part of the southern China. Previous studies (Yu et al. 2007b; Li et al. 2008) mentioned that the highest surface air temperature and strongest instability in the lower troposphere in the afternoon are benefit to the trigger of the convection. However, it is generally unfavorable for the formation and maintain of stratiform clouds in the afternoon ( $\mathrm{Li}$ et al. 2003). With the development of the convection, under certain conditions the cumulonimbus capillatus quickly degrades and dissipates, 
Fig. 9 Same as Fig. 3, but for sub-Region A and sub-Region B
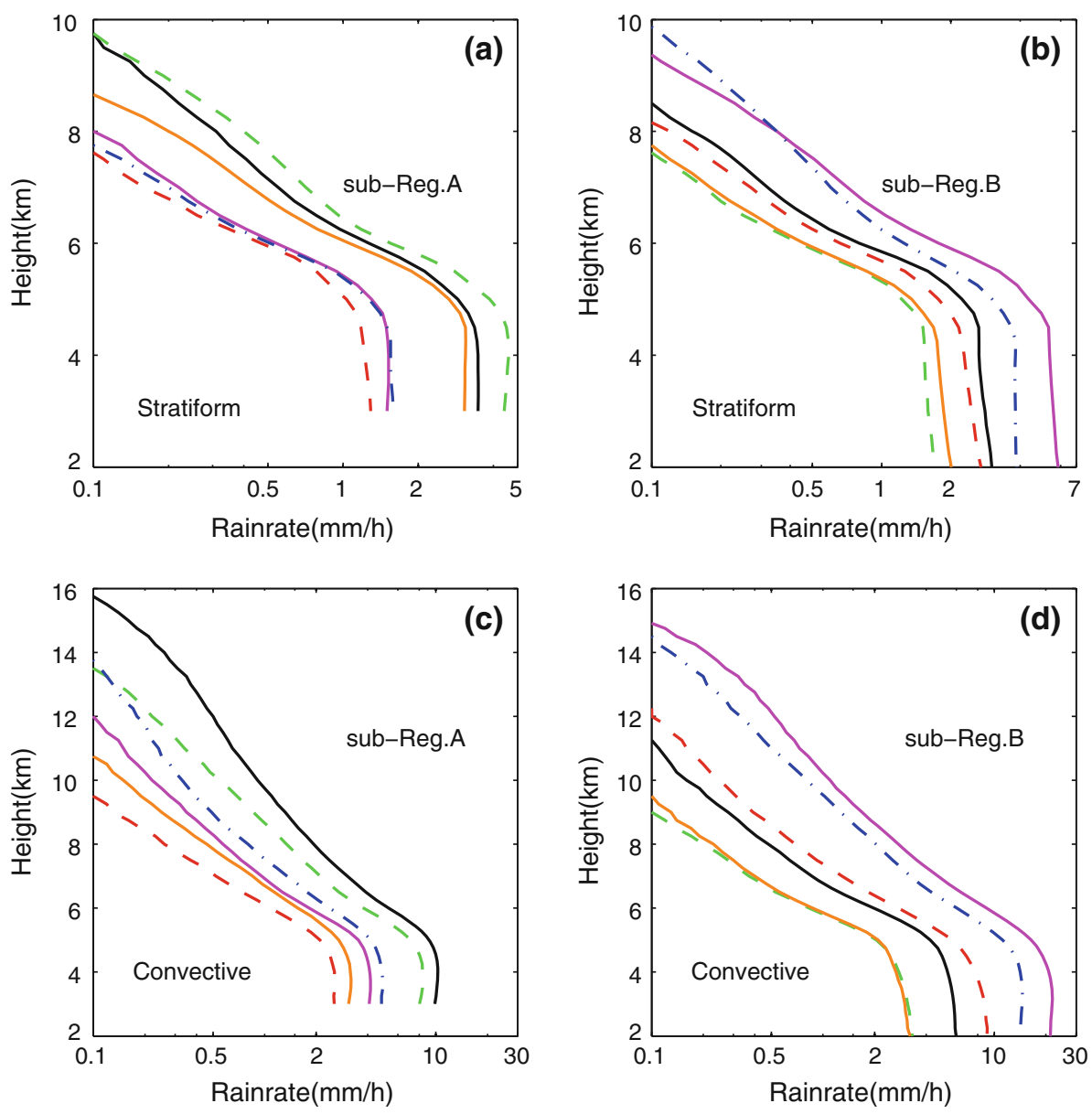

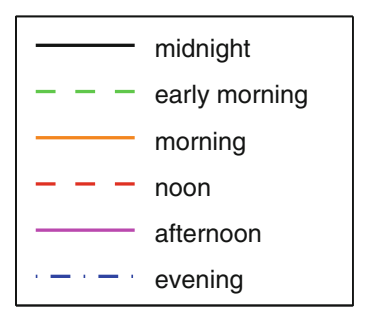

then altostratus opacus or nimbostratus may form. Although the total amount of these stratiform clouds is relatively small, the stratiform clouds can produce considerable rainfall. Even if there were no stratiform cloud, stratiform precipitation can also exist in the old convection (Houze 1997). Stratiform precipitation and convection may be not absolutely exclusive. Therefore, with the high frequency of convection, precipitating stratiform clouds and stratiform precipitation may be generated from the decaying convective cloud. The processes may contribute to the peak of stratiform rainfall in the afternoon. For long-duration rainfalls, the consistent latenight maximum for the stratiform and convective precipitation over a large part of the southwestern contiguous China may be related to mesoscale convective systems (MCSs) (Yu et al. 2007b). The MCSs are strongest after midnight and a long duration may be necessary for the moisture accumulation and isolated convection cells growing into well organized MCSs before the rainfall peaks.

An interesting feature of the precipitation diurnal cycle over the southern China is the solid diurnal phase of the two sub-regions. Over the eastern periphery of the Tibetan Plateau, precipitation has a solid late-night peak. The largest rise of stratiform profile also occurs between the evening and midnight. Besides, the convective rain top has a comparable rise (about $2 \mathrm{~km}$ ) between evening and midnight with that (about $2.5 \mathrm{~km}$ ) between the noon and afternoon. With large cloud optical depth and small diurnal amplitude (Yu et al. 2004; Li et al. 2003, 2008), the lower troposphere is more stable in the afternoon over the southwestern China than the southeastern China and the 
probability of precipitation is relatively low. Because of both the nighttime middle-level cold advection originated from the plateau cold surface and the long-wave radiative cooling at the top of cloud, the instability may be triggered and reach the maximum around the late-night. Areas of sub-Region B mostly locate in either the coastal or inland mountain regions (as shown in Fig. 7). The consistent lateafternoon maximum over sub-Region B might be affected by the complex land-sea and mountain-valley breezes ( $\mathrm{Yu}$ et al. 2008). The strongest solar heating in the afternoon may also contribute to the consistent late-afternoon peak.

This research offers a more comprehensive cognition about the characteristics of the precipitation diurnal cycle over the southern contiguous China and provides a standard for the test of parameterizations in numerical models. To further verify above processes and mechanisms, it is necessary to grasp both the categorization of rainfall types and the whole evolution processes of rainfall events. Therefore, in the following studies, the TRMM PR data and the station rain gauge data will be further synthesized to investigate these questions.

Acknowledgments Satellite radar data was provided by NASA Goddard Space Flight Center and JAXA/EORC through the TRMM project. This research was jointly supported by the Major State Basic Research Development Program of China (973 Program) under grant No. 2004CB418304, the National Natural Science Foundation of China under grants No. 40625014, 40675027, and 40730950.

Open Access This article is distributed under the terms of the Creative Commons Attribution Noncommercial License which permits any noncommercial use, distribution, and reproduction in any medium, provided the original author(s) and source are credited.

\section{References}

Dai A (2001) Global precipitation and thunderstorm frequencies part II: diurnal variations. J Clim 14:1112-1128. doi:10.1175/15200442(2001)014<1112:GPATFP > 2.0.CO;2

Dai A, Giorgi F, Trenberth KE (1999) Observed and model-simulated diurnal cycles of precipitation over the contiguous United States. J Geophys Res Atoms 104:6377-6402. doi:10.1029/98JD02720

Fu Y, Lin Y, Liu G et al (2003) Seasonal characteristics of precipitation in 1998 over East Asia as derived from TRMM PR. Adv Atmos Sci 20:511-529. doi:10.1007/BF02915495
Fu Y, Liu G, Wu G et al (2006) Tower mast of precipitation over the central Tibetan Plateau summer. Geophys Res Lett 33:L05802. doi:10.1029/2005GL024713

Houze RA Jr (1997) Stratiform precipitation in region of convection: a meteorological paradox? Bull Am Meteorol Soc 78:2179 2196. doi:10.1175/1520-0477(1997)078<0021:IBGSAA >2.0. $\mathrm{CO} ; 2$

Iguchi T, Kozu T, Meneghini R et al (2000) Rain-profiling algorithm for the TRMM precipitation radar. J Appl Meteorol 39:2038-2052. doi:10.1175/1520-0450(2001)040<2038:RPAFTT >2.0.CO;2

Li Y, Yu R, Xu Y et al (2003) The formation and diurnal changes of stratiform clouds in southern China. Acta Meteorol Sin 61:733743

Li J, Yu R, Zhou T (2008) Seasonal variation of the diurnal cycle of rainfall in the southern contiguous China. J Clim 21:6036-6043. doi:10.1175/2008JCLI2188.1

Liu G, Fu Y (2001) The characteristics of tropical precipitation profiles as inferred from satellite radar measurements. J Meteor Soc 79:131-143. doi:10.2151/jmsj.79.131

Nesbitt S, Zipser E (2003) The diurnal cycle of rainfall and convective intensity according to three years of TRMM measurements. J Clim 16:1456-1475

Sorooshian S, Gao X, Hsu K et al (2002) Diurnal variability of tropical rainfall retrieved from combined GOES and TRMM satellite information. J Clim 15:983-1001. doi:10.1175/15200442(2002)015<0983:DVOTRR >2.0.CO;2

Steiner M, Houze R Jr, Yuter S (1995) Climatological characterization of three-dimensional storm structure from operational radar and rain gauge data. J Appl Meteorol 34:1978-2007. doi: 10.1175/1520-0450(1995)034<1978:CCOTDS > 2.0.CO;2

Tao W, Lang S, Simpson J et al (1993) Retrieval algorithms for estimating the vertical profiles of latent heat release: their applications for TRMM. J Meteorol Soc Jpn 71:685-700

Wallace J (1975) Diurnal variations in precipitation and thunderstorm frequency over the conterminous United States. Mon Weather Rev 103:406-419. doi:10.1175/1520-0493(1975)103<0406: DVIPAT $>2.0 . \mathrm{CO} ; 2$

Yang G, Slingo J (2001) The diurnal cycle in the tropics. Mon Weather Rev 129:784-801. doi:10.1175/1520-0493(2001)129< 0784:TDCITT>2.0.CO;2

Yu R, Wang B, Zhou T (2004) Climate effects of the deep continental stratus clouds generated by Tibetan Plateau. J Clim 17:27022713. doi:10.1175/1520-0442(2004)017<2702:CEOTDC $>2.0$. $\mathrm{CO} ; 2$

Yu R, Zhou T, Xiong A et al (2007a) Diurnal variations of summer precipitation over contiguous China. Geophys Res Lett 34:L01704. doi:10.1029/2006GL028129

Yu R, Xu Y, Zhou T et al (2007b) Relation between rainfall duration and diurnal variation in the warm season precipitation over central eastern China. Geophys Res Lett 34:L13703. doi: 10.1029/2007GL030315

Yu R, Li J, Chen H (2008) Diurnal variation of surface wind over central eastern China. Clim Dyn. doi:10.1007/s00382-008-0487-3 